\title{
Papillary Renal Cell Carcinoma with Extensive Osseous Metaplasia: A Case Report
}

\author{
Neelam Sharma ${ }^{1 *}$, Vinita Kothari ${ }^{2}$ and Vimal Mehta ${ }^{3}$ \\ ${ }^{1}$ Assistant consultant, Central Lab, Indore (MP)-India \\ ${ }^{2}$ Consultant and lab director, Central lab, Indore (MP)-India \\ ${ }^{3}$ Consultant surgeon, Mehta nursing home, Mandasour (MP)-India
}

\begin{abstract}
Calcification is frequently seen histopathological and radiological finding in renal cell carcinoma (RCC). Occurrence of metaplastic bone is rare feature and majority are reported in clear cell renal cell carcinoma. We report a case of papillary renal cell carcinoma with extensive osseous metaplasia.
\end{abstract}

Keywords: Papillary Renal Cell Carcinoma, Osseous Metaplasia

\section{Introduction}

Renal cell carcinoma (RCC) constitutes about $2 \%$ of total human cancers and clear cell variant is the most common histologic subtype. Papillary RCC comprises about 10\% of renal cell carcinoma. ${ }^{[1]}$ Occurrence of metaplastic bone within the renal mass is quite unusual histomorphological feature though calcific foci have been reported frequently. Underlying pathogenic mechanism can be osseous differentiation or osseous metaplasia. This case represents metaplastic process. To best of my knowledge less than 30 cases have been reported in the world literature. Clear cell variant is most common histologic variant associated with metaplasia whereas only three cases have been reported with papillary renal cell carcinoma. We are adding fourth case of papillary renal cell carcinoma with extensive osseous metaplasia.

\section{Case Report}

55 year female with complain of abdominal pain visited to surgical clinic. On routine investigation ultrasonography showed a heterogeneous mass in right kidney. The computerized tomography (CT) scan of the abdomen confirmed $9 \mathrm{~cm}$ large heterogeneous right renal mass with calcific foci as shown in figure 1. The patient underwent open right radical nephrectomy. Removed nephrectomy specimen on gross examination revealed a tumour measuring 10x8x6 cm sparing thin peripheral rim of normal renal parenchyma. This was hard to cut and giving grating sensation. The cut surface showed well encapsulated grey white to red brown friable mass having focal papillary areas with hard bony area measured $5 \times 4 \mathrm{~cm}$. The renal sinus and pelvis were free of tumour. There was no evidence of capsular infiltration and perinephric fat was free (Figure 2).
Histopathological examination revealed papillary renal cell carcinoma type I, Fuhrman nuclear grade 2 with extensive areas of metaplastic bone formation in the stroma as shown in figure 3 .

\section{Discussion}

Calcification is frequent histopathological finding in renal cell carcinoma. ${ }^{[1]}$ Daniel reported $10.3 \%$ of Renal cell carcinoma had calcific foci, based on a review of 2709 renal masses at the mayo clinic. ${ }^{[2]}$ Osseous metaplasia within the $\mathrm{RCC}$ is a rare feature. The exact mechanism of ossification is not known although it might involve metaplasia or dedifferentiation that is osteosarcomatous differentiation which carries poor prognosis. Bone morphogenic protein (BMP) has been suggested as a possible cause of metaplastic bone formation in RCC and tumour of other organs. ${ }^{[3,4]}$ This was suggested to represent secondary to ischemia, necrosis or inflammation in the tumour proper or surrounding connective tissue. Ossification is not defined as a prognostic significant in RCC because of very limited number of cases reported in literature. Study comprises of large number of patients with long term follow up is needed. However several studies demonstrated this as a significant prognostic marker in RCC and usually representative of an early stage, without invasion or metastasis. ${ }^{[5,6]}$ Cribbs et al. ${ }^{6}$ reported a clear cell RCC with ossification in which no recurrence or metastasis was observed for a follow up of 25 years, therefore RCC with osseous metaplasia implies a more favourable prognosis although some reports are contradicting this, suggesting that ossification is actually associated with high grade tumour and a poor prognosis. [7] There has been fewer than 30 cases reported in the literature. Osseous metaplasia has been associated mostly 


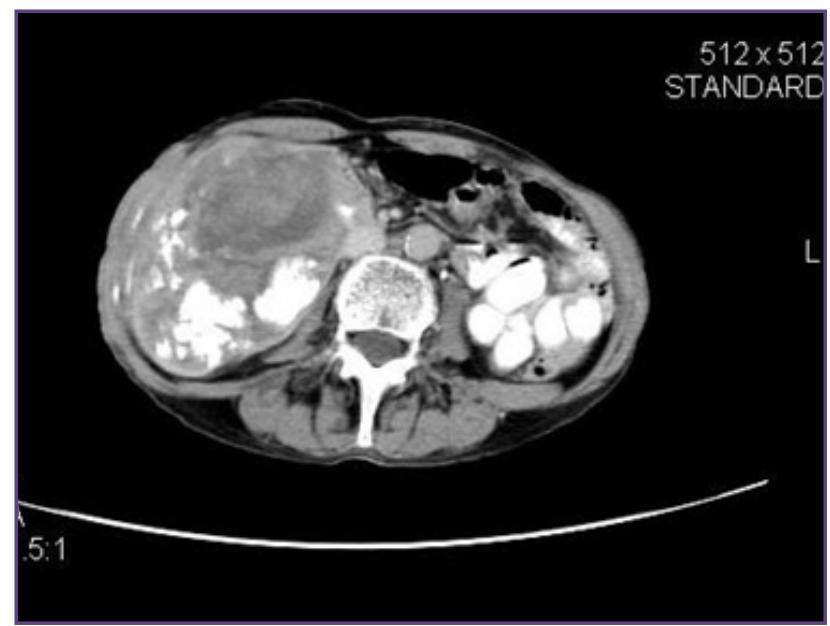

Fig. 1: CT scan of abdomen revealed a large solid well defined right renal mass with calcific foci corresponding to extensive metaplastic bone formation.

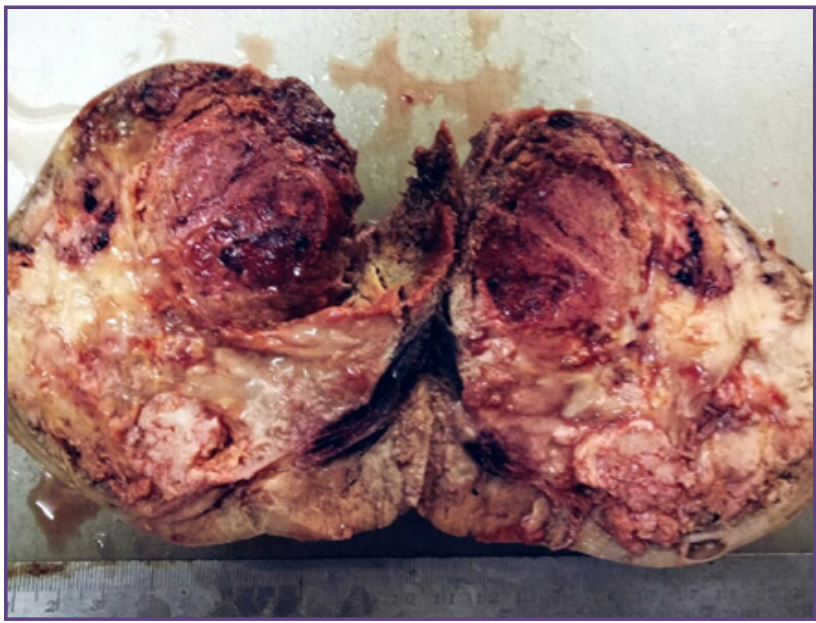

Fig. 2: cut surface of right nephrectomyspecimen showing solid,well-circumscribed heterogeneous, grey tan to brown mass replacing almost entire renal parenchyma with thin peripheral rim of uninvolved kidney and difficult to cut bony hard areas (red arrow).
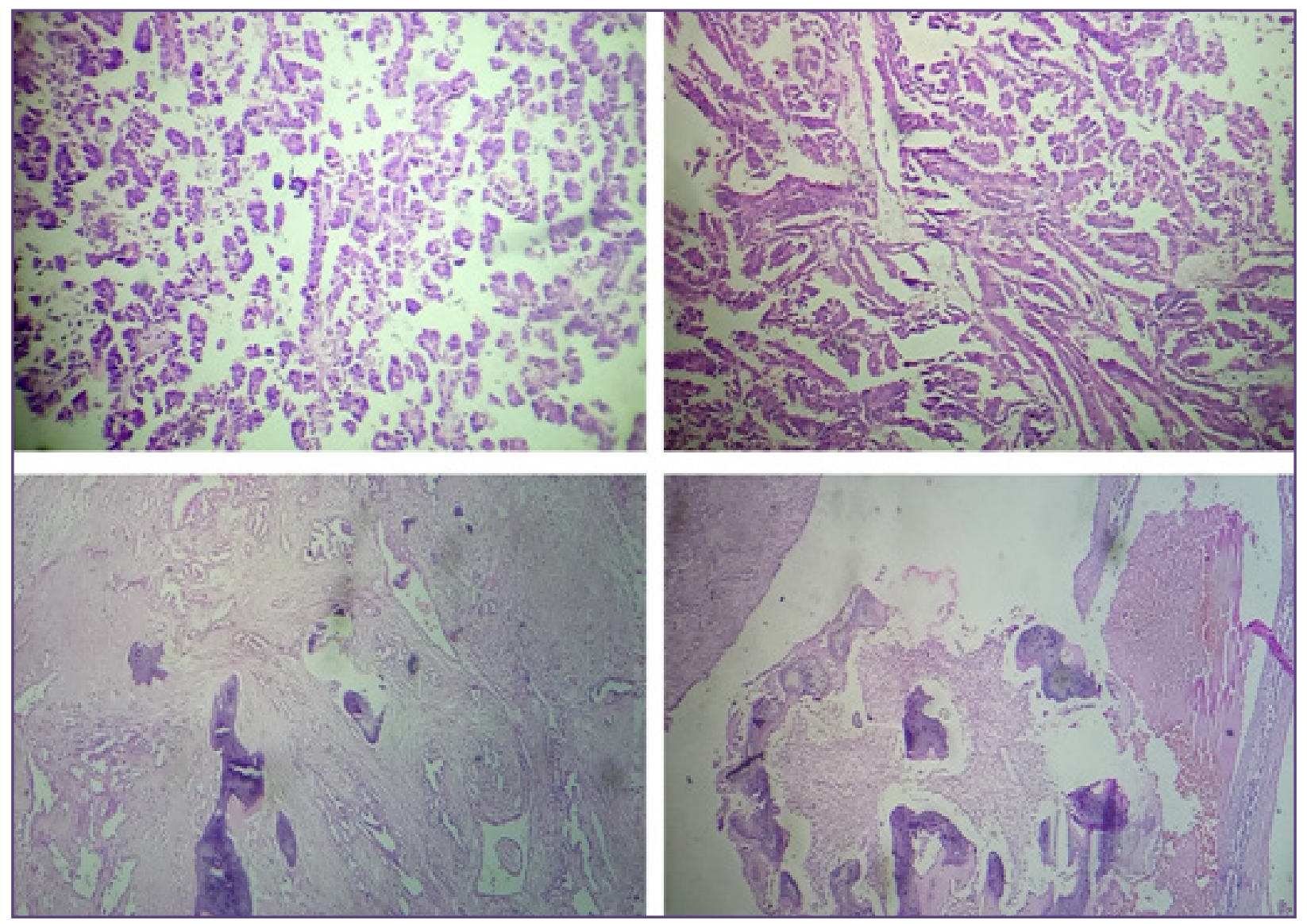

Fig. 3: Haematoxylin-eosin stained sections revealed neoplasm with papillary architecture. Papillae are lined by a single layer of cells with scant cytoplasm and low nuclear gradeconcluded papillary renal cell carcinoma type I of Fuhrmangrade2 (upper right \&left; magnification: 10x) and extensive osseous metaplasia (lower right\& left; magnification: 10x). 
with clear cell type RCC and chromophobe RCC. ${ }^{[6-9]}$ Only 3 cases reported in world literature which is associated with papillary RCC. ${ }^{[10-12]}$ In conclusion, papillary RCC with osseous metaplasia is rare finding, its prognostic significance need to be investigated by large follow up study.

\section{References}

1. Eble JN, Sauter G, Epstein JI, Sesterhenn IA (Eds): WHO classification of tumors. Pathology and genetics of tumors of the urinary system and male genital organs. IARC press: Lyon 2004.

2. Daniel WW Jr, Hartman GW, Written DM, Farrow GM, Kelalis PP. Calcified renal masses: A review of ten year experience at the Mayo clinic. Radiology 1972;103:503-8.

3. Kwak C, Park YH, Kim IY, Moon KC, Ku JH. Expression of bone morphogenetic proteins, the subfamily of the transforming growth factor - beta superfamily, in renal cell carcinoma. J Urol 2007;178:1062-7

4. Kefeli M, Yildiz L, Aydin O, Kandemir B, Faik Yilmaz A. Chromophobe renal cell carcinoma with osseous metaplasia containing fatty bone marrow element: A case report. Pathol Res Pract 2007;203:749-2.
5. Sostre G, Johnson JF 3rd, Cho M. Ossifying renal cell carcinoma. Pediatr Radiol 1998;28: 458-60.

6. Cribbs RK, Ishaq M, Arnold M, O’Brien J, Lamb J, Frankel WL. Renal cell carcinoma with massive osseous metaplasia and bone marrow elements. Ann Diagn Pathol 1999;3:294-9.

7. Bielsa O, Lloreta J, Arango O, Serrano S, Gelabert-Mas A. Bone metaplasia in a case of bilateral renal cell carcinoma. Urol Int 2001;66:55-6.

8. Murugan P, Basu D, Manikandan R, Dorairajan LN, Kumar S. Osseous metaplasia in renal cell carcinoma: report of a rare case. Indian J Pathol Microbiol 2008;51:399-01.

9. Agarwal S, Bohara S, Jha R, Khurana N, Agarwal PN. Clear cell renal cell carcinoma with osseous metaplasia: Rare case report. J Cancer Res Ther 2015;11:1039.

10. Leung C, Trainer V, Short E, Venkatanarasimha N. A case of ossifying papillary renal cell carcinoma. Urology 2012;80:11-2.

11. Khurram M, Tranesh G, Hamza A, Qu H. Massive Osseous Metaplasia in Papillary Renal Cell Carcinoma: A Rare Entity. Am J Clin Pathol 2015;144:320

12. Maioli H, Sharma M, Crane GM, Wu G, Miyamoto H. Renal cell carcinoma with osseous metaplasia: A case report and literature review. Integr Cancer Sci Therap 2017;4:1-4

*Corresponding author:

Dr. Neelam Sharma, Assistant Consultant, Central lab, Mezzanine floor, Yashwant plaza, Indore (MP)- 452001 INDIA

Phone: +91 7354678944, 9739651385

Email: dr.neelamsharmagrmc@gmail.com

Financial or other Competing Interests: None. 